\title{
Perceptions of Higher Education Health Science Faculty on Debriefing After Simulation-Based Activities
}

\author{
Maureen Ellen Johnson \\ University of St. Augustine for Health Sciences
}

Higher education faculty striving to be academically competitive can adopt debriefing after simulationbased activities to help transition health science students from classroom skills to clinical competence. A qualitative study of twelve semi-structured interviews found faculty's perceptions and experiences of learning how to debrief were initially critical and skeptical; for trialing debriefing, faculty were nervous and felt awkward; for adopting and experimenting debriefing styles, faculty were curious to learn different techniques; and for overall perceptions, faculty felt debriefing was a valuable, immersive teaching style that increased student learning and skill performance. Innovative teaching strategies, like debriefing, promote improved clinical competence.

Keywords: debriefing, simulation, higher education, health science academia, innovative teaching delivery

\section{INTRODUCTION}

An emerging innovation in health science education is debriefing after simulation-based activities (Bethea, Castillo, \& Harvison, 2014). Debriefing is a vital component of simulation-based pedagogy as higher education simulation-based experiences do not effectively transfer learning into clinical practice without debriefing sessions facilitated by trained faculty (Decker et al., 2013; Nash \& Harvey, 2017; Reierson, Haukedal, Hedeman, \& Bjork, 2017).

As debriefing is a deliberate process, clinical educators and higher education faculty require a specific skill set to debrief (Dufrene \& Young, 2014). Previous studies have shown the effectiveness of faculty conducting debriefing sessions, (Bethea et al., 2014; Dufrene \& Young, 2014; Sabus \& Macauley, 2016; Saylor et al., 2016), various debriefing methods (Ayres et al., 2015; Bong et al., 2017; Kolbe, Marty, Seelandt, \& Grande, 2016; Krogh, Bearman, \& Nestel, 2016), and student perceptions from debriefing sessions (Beischel, 2013; Oxelmark, Amoroe, Carlzon, \& Rysedt, 2017). However, little research has been conducted on the perceptions and experiences among health science faculty who have undergone training and adjusted their teaching delivery to include debriefing.

Understanding the innovation-decision process provides increased insights into faculty developmental needs, so curriculum writers can design more and better experiential teaching opportunities in health science education (Cheng et al., 2015; Landeen et al., 2015). Such insight may also help ensure that prelicensed occupational therapy and physical therapy students receive the best education possible to facilitate their shift of classroom knowledge into clinical skills required for safe clinical practice. The purpose of this qualitative study was to explore the perceptions and experiences of higher education health science faculty during and after their adoption of debriefing after simulation-based activities. 


\section{METHODS}

This qualitative research study was conducted using virtual one-on-one semistructured interviews.

\section{Participants}

Purposive sampling was used for recruitment of participants from a university comprised of four different campuses all containing newly constructed hospital-style simulation centers. As part of their teaching delivery, all health science faculty were encouraged to include simulation and debriefing in their courses. The participants were recruited by receiving a university-wide e-mail seeking volunteer participants with the outline of the research study and the inclusion criteria: (a) faculty identified themselves as currently working for the university, (b) faculty indicated that they have participated in at least one simulation and debriefing training session, (c) faculty have conducted at least one debriefing session after simulation-based activities. The informed consent was attached to the e-mail.

\section{Data Collection}

If the potential participants were interested and met inclusion criteria, they were instructed to read the informed consent and reply "I consent" to the e-mail. Virtual interviews were used due the locations of the campuses and the faculty's familiarity of this platform for their weekly work-related duties. Appendix A provides the semi-structured interview questions.

Participants were reminded of their voluntary participation, freedom to terminate, and the anonymity of their statements and interview transcriptions. The interviewer asked participants to describe their experiences during debriefing training and delivery in their courses. Data collection continued until saturation with the $12^{\text {th }}$ participant. This research study was approved by the university's' Institutional Review Board and oral consent was obtained prior to each interview.

\section{Data Analysis}

All interviews were audio recorded, transcribed, analyzed, and coded by the investigator. The data were reviewed to interpret the results of the study analyzing context behaviors and comments to look for patterns. Using constant comparison analysis, the investigator discovered the first round of codes, which were modified and expanded as the analysis progressed. After the second round of coding, the codes were organized into categories and underlying themes emerged. To increase validity and trustworthiness, triangulation and member checking were conducted. Triangulation of the data was achieved by interviews, memo notes during the interviews, and reflexive journaling immediately after the interviews.

\section{RESULTS}

Twelve participants (female $n=10$; male $n=2$ ) were interviewed before reaching thematic saturation with occupational therapy faculty $(n=6)$ and physical therapy faculty $(n=6)$. Teaching experience ranging from 2 years to 25 years of experience. Prior to this faculty development training, no participant had immersive simulation or debriefing experience. A conceptual framework explained the participant's adoption of this innovation teaching delivery. Participants began with an awareness of using the debrieifng technique, developed their attitude, and decided to adopt or discard this innovation. All participants adopted and even endorsed the innovation of debriefing (Rogers, 2003).

Additionally, the experiential learning cycle (Kolb, 1984) explained how participants entered this cycle when learning debriefing strategies. Initially, participants learned how to conduct debriefing with templates (concrete experience). Then, they reflected on their experience of leading the debriefing session (reflective observation). Next, the reflections prompted new ideas or modifications to the debriefing template for their individual courses (abstract conceptualization). Finally, the participants applied their new ideas during new debriefing sessions (active experimentation). The success or failure of the experiential learning process influenced how participants adopted using debriefing sessions in their courses. 
Based on the interview data, 4 major themes emerged that captured the participants' perceptions and experiences of debriefing after simulation-based activities: valuable immersive experience, criticality during training, nervous and uncomfortable with initial delivery, and full adoption of this innovative teaching delivery with experimentation. Member checking was performed to provide dependability and trustworthiness. TABLE 1 lists each research question with code words and identified themes.

TABLE 1

FOUR MAJOR THEMES WITH REPRESENTATION QUOTATIONS FROM QUALITATIVE ASSESSMENT OF FACULTY'S PERCEPTIONS AND EXPERIENCES WITH DEBRIEFING AFTER SIMULATION-BASED ACTIVITIES

\begin{tabular}{|c|c|c|}
\hline $\begin{array}{l}\text { Research Question } 1 \text { that } \\
\text { Prompted Emerging Themes }\end{array}$ & Codes & Quotes \\
\hline \multirow[t]{4}{*}{$\begin{array}{l}\text { RQ1: What are the perceptions of } \\
\text { higher education health science } \\
\text { faculty trained in effective } \\
\text { debriefing strategies when they } \\
\text { incorporate debriefing sessions } \\
\text { after simulation-based activities? }\end{array}$} & Valuable & $\begin{array}{l}\text { "Debriefing is probably the most effective way } \\
\text { for me to ensure the students are meeting the } \\
\text { objectives and more importantly are able to } \\
\text { effectively utilize their skills as clinicians with } \\
\text { patients." } \\
\text { "[Students] have to sit and process what } \\
\text { they...did, that is when they are really } \\
\text { growing. They have to in their minds problem- } \\
\text { solve right there and find a way to make it } \\
\text { work." } \\
\text { "I see on the other end, when students who } \\
\text { have had the simulation experiences come to } \\
\text { fieldwork, they are more successful." }\end{array}$ \\
\hline & $\begin{array}{l}\text { Immersive } \\
\text { experience }\end{array}$ & $\begin{array}{l}\text { "putting the whole picture together is what I } \\
\text { really find, those higher-level learning } \\
\text { objectives of multi-tasking and combining } \\
\text { numerous skills in the patient care } \\
\text { communication." } \\
\text { "absolutely ties it together." }\end{array}$ \\
\hline & $\begin{array}{l}\text { Self-reflections } \\
\text { increase learning } \\
\text { and performance }\end{array}$ & $\begin{array}{l}\text { "we [faculty] have to grasp that it is in } \\
\text { reflection that learning takes place." } \\
\text { "it is really important to not only see them } \\
\text { doing their hands-on techniques but how do } \\
\text { they utilize this information to bring them } \\
\text { through the patient care management model." } \\
\text { "for me that ability for them to self-reflect and } \\
\text { take in all of that information and figure out } \\
\text { how to use it or how that is going to drive their } \\
\text { treatment or interventions is huge." }\end{array}$ \\
\hline & & $\begin{array}{l}\text { "I'm pleasantly surprised about the carryover } \\
\text { that I couldn't have a vision of how students } \\
\text { learn motor skills without doing the motor } \\
\text { skills but what the sim is actually doing is that } \\
\text { they learn the motor skills first [in a laboratory } \\
\text { class] and ... then learn ... from watching } \\
\text { another person perform what you have } \\
\text { learned." }\end{array}$ \\
\hline
\end{tabular}


Create safe space "What resonated most with me was when we discussed the principles of psychological safety

RQ2: What are the perceptions of higher education health science faculty during their experiential training on how to conduct effective debriefing sessions? not only for the student but also for the actors and how utilization of simulation really is our best opportunity at preparing students for their future practice."

"We wanted to create a space where they really had to think on their feet and critically analyze what they were doing."

Deliberate, open- "how you ask questions makes a difference." ended questions "you have to ask open-ended questions and you have to also be able to make sure you pause between asking those questions. Kind of look around the room."

RQ3: What do higher education health science faculty experience when putting their training of conducting debriefing sessions into practice?

"It was rough. I tried to mimic or model exactly what I saw in the training."

"I really underestimated the role and the value of the facilitator."

"I was fairly nervous as an instructor because it was a new technique and it was a different way of approaching talking to the class."

Hard not to teach or jump in to fix "because you want to teach, and I had to have this repeated mantra in my mind to stop teaching during the debriefing and to just listen." "getting caught up in those teaching moments that you were trying to avoid like us dominating and teaching during that facilitation. That was a hard habit to kick for myself."

"It was really challenging and even to this day it still is challenging to not want to automatically give them that specific feedback like "oh you forgot to do this" so that was really hard for me those first few times.

And I found it was a struggle for me to get out of that [teaching lecturing] mindset."

Awkward "At first it is always a little awkward because I silence don't need to jump right in and say something" "Embrace the silence, the awkward silence that will happen with students."

"allowing the silence is a great learning tool that I believe is underutilized."

RQ4: How did the experiences of Facilitate and learning how to effectively debrief and initial trials of conducting debriefing sessions relate to faculty's adoption of incorporating debriefing sessions after simulation-based activities?
"I might ask a question and then they start to jump in and as one speaks, another one speaks, and I really feel that the students are leading it." It's not me. I am initiating it, I am guiding it, but they are the ones who are really talking." 


$\begin{array}{ll}\text { Student self- } & \text { "In the debriefing is where you see the wheels } \\ \text { reflections } & \text { turning and clicking. You know that that } \\ & \text { reflection is working." } \\ & \text { "You can see that critical thinking and } \\ \text { problem-solving going on right there in that } & \text { room." } \\ & \text { "Faculty has to understand the importance of } \\ & \text { the reflection component and how that is the } \\ \text { precursor to the learning." } & \text { "The more and more I am getting used to it, I } \\ \text { Trying different } & \text { am finding that my debriefings are getting } \\ \text { debriefing } & \text { longer and based on what I am reading that is } \\ & \text { where the students are learning and growing } \\ & \text { and self-reflecting and allowing them to } \\ \text { participate." } & \text { "faculty have had the opportunity to build their } \\ & \text { "teaching toolkit" with this innovative teaching } \\ & \text { style." } \\ & \text { "I think of my objectives much more. I have } \\ & \text { the objectives in my mind, not just what I want } \\ \text { to get out of the actual simulation but from my } \\ \text { debriefing." } \\ \text { "Honestly, I have a cheat sheet of phrases that } \\ \text { will get the students to talk more because they } \\ \text { don't always come naturally to me." }\end{array}$

\section{Adoption of Debriefing After Simulation-Based Activities}

The study revealed that, although initially skeptical and nervous during early use, participants felt the use of debriefing after simulation-based activities in their course was a valuable experience for their students. All participants reported that they had adopted debriefing strategies after simulation-based activities in their courses.

\section{Valuable Immersive Experience}

The first theme that emerged was that all faculty felt that debriefing was a valuable, immersive experience prompting student self-reflections which appeared to increase their overall concept learning and skill performances in future simulations. All the research participants expressed the value of debriefing as a cumulative strategy of collectively analyzing, applying, and synthesizing a simulated therapy session to provide a well-rounded opportunity for the students to get a feel of a real treatment session.

\section{Student Self-Reflections Improve Performance}

The participants' perceptions were overwhelmingly positive in support of debriefing after simulationbased activities in their courses. Three participants shared their experiences of students' lasting abilities during their clinical fieldwork outside the walls of the classroom.

\section{Surprise/Criticality of Teaching Method}

Based on the interview responses, the most significant challenge for the participants to overcome was the teaching methodology. As traditional educational paradigms position faculty standing and lecturing from a podium in front of the seated rows of students, debriefing involves positioning all participants, including faculty, into a giant circle with faculty guiding the conversation and students doing most of the talking (Hall \& Tori, 2017). 


\section{Create Safe Space}

According to best practice standards for debriefing, creating a psychologically safe space is crucial for student engagement and learning (Hall \& Tori, 2017; Rojas et al., 2017; Wilson \& Wittmann-Price, 2014). Six participants commented on the novelty of creating a safe space during debriefing where students could feel safe enough to share their experiences from their anxiety producing simulation. Several participants responded that they appreciated learning the importance of creating a safe space for both the physical and the psychological environments, something they had "never really thought of before." Two participants commented on the importance of the debriefer to maintain a neutral presence using neutral body language and tone of voice to promote conversation among the students for best practice guidelines (Dufrene \& Young, 2014; Hall \& Tori, 2017; Rojas et al., 2017; Wilson \& Wittmann-Price, 2014).

\section{Deliberate, Open-Ended Questions}

The use of deliberate, open-ended questions during the debriefing sessions was also mentioned as a notable element from the debriefing training. As the faculty in-training were shifting from lecturing to students to facilitating discovery within students, one participant realized the goal of asking deliberate, open-ended questions is for "trying to draw information from those who participated in the simulation and facilitate the discovery and discussion." Participant 4 recognized from the training session that if the debriefer used a list of deliberate, open-ended questions as a guide during the debriefing, then "the debriefing process kind of evolves as you are doing it." Even though most of the participants were highly critical and skeptical during their early training on how to effectively debrief, all 12 eventually accepted debriefing as an effectual way to educate students.

\section{Nervous and Uncomfortable}

The participants reported that they led their first debriefing session approximately 2-3 months after their training sessions. Even though most of them used a script or a list of questions or phrases as prompts during the debriefing sessions, they shared common descripted feelings of nervousness, challenging, and at times uncomfortable. Nine participants claimed that their first debriefing process was "nerve-wracking." Participant 8 admitted, "I was fairly nervous as an instructor because it was a new technique, and it was a different way of approaching talking to the class."

\section{Awkward Silence}

Debriefing should occur immediately following the simulation-based activity and the length of the debriefing session be at least two times the length of the simulation (Dufrene \& Young, 2014). All participants revealed how difficult it was to shift to this novel teaching delivery where the teachers need to be patient and quiet in order to allow the students to do most of the talking. Typically, the faculty have that urge to fill the silence with lecturing as evident by their responses. "At first, it was a little awkward."

\section{Hard Not to Teach or Jump In}

The participants reported it was hard waiting during the awkward silence and not to just lecture the students. One participant explained the struggle within themselves to hold back "because I don't need to jump right in and say something." Participant 8 explained, "because you want to teach, and I had to have this repeated mantra in my mind to stop teaching during the debriefing and to just listen."

\section{Adoption of Debriefing After Simulation-Based Activities}

All the participants overwhelmingly agreed upon the valuable and long-lasting benefits of utilizing debriefing after simulation-based activities. Many responded in detail their current debriefing procedures with a focus on facilitating and guiding the discussion and not just lecturing. In addition, 9 participants claimed they have experimented with different styles of debriefing and strategies used during their debriefing sessions. 


\section{Student Self-Reflections}

The participants collectively agreed on the value of facilitating self-reflection in the students and this awareness was a key to their adoption of debriefing after simulation-based activities in their courses. Participant 7 stated, "Debriefing... is helping metacognitive thoughts on what happened there, what could have happened there... and what is it that you could have done differently?" Participant 6 agreed with similar word choices as Participant 7 "because I can see ... that there are wheels turning in the student's minds."

\section{Experimenting With Different Debriefing Techniques}

As all participants have included the use of debriefing after simulation-based activities in their course, they also started experimenting with new methods and techniques. Participant 6 explained that faculty could build their "teaching toolkit." Participant 11 described, "I am playing around with different ideas and strategies."

\section{DISCUSSION}

This research is the first study of higher education health science faculty perceptions of debriefing after simulation-based activities in their courses. The participants were respected health science faculty with years of experience in their teaching role at the time of this study. Transitioning through the innovationdecision process was a calculated progression that was at risk of rejection at each stage with each participant (Rogers, 2003).

Based on the responses to the interviews, the participants indicated that they transitioned through Rogers's stages of the innovative-decision process as they were learning and experimenting with debriefing after simulation-based activities before they eventually adopted this innovation in their routine teaching delivery. Additionally, using the adult learning theory (Kolb, 1984), adults learn best through hands-on experience. The health science faculty participants used concrete experience and reflective observation in their debriefing training sessions and abstract conceptualization when they were reflecting on their performance and learning experience. The last part of the learning cycle is active experimentation where the faculty participants reported experimenting with different debriefing methods in their courses. Although these stages need to be followed sequentially, the adult learner can enter and exit at any time in this process (Kolb, 1984).

Four major themes related to participants' perceptions and experiences of debriefing after simulationbased activities were identified. First, participants collectively commented on the value of this immersive experience for the students and the use of student self-reflections during the debriefing process that positively influenced student skill performance on subsequent simulations and practical testing. The research data indicated that all participants had adopted and successfully incorporated the use debriefing after simulation-based activities in at least one of their courses.

The second theme that emerged was criticality and skepticism of this teaching delivery. Responses from the participants shed light on the novelty of using debriefing after simulation-based activities and the required shift in teaching model that each participant had to experience for training. Kolb's first two stages of concrete experience and reflective observation are relative to the participants' debriefing training as revealed in their responses to the interview questions. All participants received formal experiential training which also included how to create a safe space and how to ask open-ended questions to the students.

The third theme that emerged focused on participants' feelings of being nervous, hard not to teach or jump in, and the awkward silence when trialing the debriefing technique for the first time in their courses. Kolb claimed that learners enter a phase of abstract conceptualization where they gain insight and make logical sense of the experience that they can draw from for future use. The final stage is active experimentation where the learners plan out and tries what they have learned (Kolb, 1984).

The last theme identified by the participants was the participants' adoption (Rogers, 2003) and active experimentation (Kolb, 1984). The final adoption is a combination of a sequence of choices and actions over time (Rogers, 2003). After the training, experiences with conducting sessions, and experimenting with different methods, all the faculty participants adopted the innovation of debriefing after simulation-based 
activities as a teaching delivery in their courses. Adoption occurs after a person successfully transitions through each of the five stages of the innovation-decision process (Rogers, 2003). Hence, the more experiences and training the faculty have, the more likely they are to continue to use debriefing in their courses and to promote its use in health science curricula.

\section{Limitations}

The health science faculty who participated in this study were employed at the same university that comprised four separate campuses. Each campus housed a uniquely constructed simulation and debriefing center. It was possible that this study reflected perceptions and experiences from faculty who were comfortable sharing their experiences of their training and debriefing sessions, hence their willingness to participate. However, these 12 participants may not represent the faculty who have been trained and who do conduct debriefing after simulation-based activities yet did not participate in this study.

The breadth of this national sample of occupational therapy and physical therapy faculty is a significant feature of this study with the blending of their data strengthening the findings. However, the participants were limited to occupational therapy and physical therapy faculty from one national university. Faculty from other universities and health care disciplines were excluded. A more complete exploration could include the experiences of allied health faculty from professions such as speech pathology, respiratory therapy, recreational therapy, and physician assistants. Therefore, this sample population for this research study could be debated on generalized findings to other occupational therapy and physical therapy faculty populations as well as to allied health education.

\section{Future Studies}

The original intent of this study was to interview 8-12 participants and have 1-2 focus groups to capture rich, thick data. However, only 12 interviews were completed. Using focus groups in future studies may capture unpredictable data that can come out of group discussions. Longitudinal studies are needed on the modifications and sustainability of those faculty who have adopted the debriefing process. Future studies should include other health science faculty from other universities that utilize debriefing after simulationbased activities in their teaching delivery.

\section{CONCLUSION}

An innovation in occupational therapy and physical therapy higher education programs is the use of hospital-style simulation centers to teach a range of required therapy skills. With this innovation comes the need for health science faculty to modify their instruction to include debriefing sessions after simulationbased activities (Dufrene \& Young, 2014; Nash \& Harvey, 2017; Saylor, Wainwright, Herge, \& Pohlig, 2016). Faculty trained in effective debriefing activities empower learners to analyze and synthesize thoughts and actions from a simulation-based experience as well as interpret the thoughts and actions that can translate into potential future clinical practice.

\section{ACKNOWLEDGEMENTS}

Thanks to the faculty who participated in this study. Thanks to the writing center for editing services. 


\section{REFERENCES}

Ayers, C.J., Binder, B.K., Lyon, K.C., Montgomery, D., Koci, A., \& Foster, W.A. (2015). The simulated hospital environment: A qualitative study applying space industry techniques. Journal of Professional Nursing, 31(1), 18-25. https://doi.org/10.1016/j.profnurs.2014.06.002

Beischel, K.P. (2013). Variables affecting learning in a simulation experience: A mixed methods study. Western Journal of Nursing Research, 35(2), 226-247. https://dx.doi.org/10.1177/0193945911408444

Bethea, D.P., Castillo, D.C., \& Harvison, N. (2014). Use of simulation in occupational therapy education: Way of the future? American Journal of Occupational Therapy, 68(Supplement_2), S32. https://doi.org/10.5014/ajot.2014.012716

Bong, C.L., Lee, S., Bwee Ng, A.S., Allen, J.C., Ling Lim, E.H., \& Vidyarthi, A. (2017). The effects of active (hot seat) versus observer roles during simulation-based training on stress levels and nontechnical performance: A randomized trial. Advances in Simulation, 2(7), 1-13. https://doi.org/10.1186/s41077-017-0040-7

Cheng, A., Grant, V., Dieckmann, P., Arora, S., Robinson, T., \& Eppich, W. (2015). Faculty development for simulation programs: Five issues for the future of debriefing training. Simulation in Healthcare, 10(4), 217-222. https://doi.org/10.1097/sih.0000000000000090

Cheng, A., Grant, V., Robinson, T., Catena, H., Lachapelle, K., Kim, J., . . . \& Eppich, W. (2016). The promoting excellence and reflective learning in simulation (PEARLS) approach to health care debriefing: A faculty development guide. Clinical Simulation in Nursing, 12(10), 419-428. https://doi.org/10.1016/j.ecns.2016.05.002

Decker, S., Fey, M., Sideras, S., Caballero, S., Rockstraw, L., Boese, T., . . Borum, J.C. (2013). Standards of best practice: Simulation Standard IV: The debriefing process. Clinical Simulation in Nursing, 9(6), S26-S29. https://doi.org/10.1016/j.ecns.2013.04.008

Dufrene, C., \& Young, A. (2014). Successful debriefing - Best methods to achieve positive learning outcomes: A literature review. Nurse Education Today, 34, 372-376. https://doi.org/10.1016/j.nedt.2013.06.026

Hall, K., \& Tori, K. (2017). Best practice recommendations for debriefing in simulation-based education for Australian undergraduate nursing students: An integrative review. Clinical Simulation in Nursing, 13(1), 39-50. https://doi.org/10.1016/j.ecns.2016.10.006

Kolb, D.A. (1984). Experimental learning: Experiences as the source of learning and development. Englewood Cliffs, NJ: Prentice-Hall.

Kolbe, M., Marty, A., Seelandt, J., \& Grande, B. (2016). How to debrief teamwork interactions: Using circular questions to explore and change team interaction patterns. Advances in Simulation, 1(29), 1-8. https://doi.org/10.1186/s41077-016-0029-7

Krogh, K., Bearman, M., \& Nestel, D. (2016). "Thinking on your feet" - A qualitative study of debriefing practice. Advances in Simulation, 1(12), 1-11. https://doi.org/10/1186/s41077-016-0011-4

Landeen, J., Pierazzo, J., Akhtar-Danesh, N., Baxter, P., van Eijk, S., \& Evers, C. (2015). Exploring student and faculty perceptions of clinical simulation: A Q-sort study. Journal of Nursing Education, 54(9), 485-491. https://doi.org/10.3928/01484834-20150814-02

Mariani, B., \& Doolen, J. (2016). Nursing simulation research: What are the perceived gaps? Clinical Simulation in Nursing, 12(1), 30-36. https://doi.org/10.1016/j.encs.2015.11.004

Nash, R., \& Harvey, T. (2017). Student nurse perceptions regarding learning transfer following highfidelity simulation. Clinical Simulation in Nursing, 13(10), 471-477. https://doi.org/10.1016/j.ecns.2017.05.010

Oxelmark, L., Amoroe, T.N., Carlzon, L., \& Rystedt, H. (2017). Students' understanding of teamwork and professional roles after interprofessional simulation-A qualitative analysis. Advances in Simulation, 2(8), 1-8. https://doi.org/10/1186/s41077-017-0041-6 
Reierson, I.A., Haukedal, T.A., Hedeman, H., \& Bjork, I.T. (2017). Structured debriefing: What difference does it make? Nurse Education in Practice, 25, 104-110. https://doi.org/10.1016/j.nepr.2017.04.013

Rogers, E.M. (2003). Diffusion of innovations (5th ed.). New York, NY: Simon \& Schuster Inc.

Rojas, D.E., Parker, C.G., Schams, K.A., \& McNeill, J.A. (2017). Implementation of Best Practices in Simulation Debriefing. Nursing Education Perspectives, 38(3), 154-156. https://doi.org/10.1097/01.nep.0000000000000111

Sabus, C., \& Macauley, K. (2016). Simulation in physical therapy education and practice: Opportunities and evidence-based instruction to achieve meaningful outcomes. Journal of Physical Therapy Education, 30(1), 3-13. https://doi.org/10.1097/00001416-201630010-00002

Sawyer, T., Eppich, W., Brett-Fleegler, M., Grant, V., \& Cheng, A. (2016). More than one way to debrief: A critical review of healthcare simulation debriefing methods. Society for Simulation in Healthcare, 11(3), 209-219. https://doi.org/10.1097/sih.0000000000000148

Saylor, J.L., Wainwright, S.F., Herge, E.A., \& Pohlig, R.T. (2016). Peer-Assessment debriefing instrument (PADI): Assessing faculty effectiveness in simulation education. Journal of Allied Health, 45(3), e27-e30. Retrieved from https://www.ncbi.nlm.nih.gov/pmc/articles/PMC5504520/

Wilson, L., \& Wittmann-Price, R.A. (Eds.). (2014). Review manual for the Certified Healthcare Simulation Educator exam. Springer Publishing Company. https://doi.org/10.1891/9780826138897

\section{APPENDIX}

\section{Question 1:}

Can you please describe and share your recollections about your learning process on how to effectively debrief after simulation-based activities?

Probes:

- Maybe what you remember most about your learning how to debrief?

- Possible thoughts or insights you had while you were learning about conducting debriefing sessions.

\section{Question 2:}

Please think back to the time from right after you were trained to conduct simulations and debriefings to the time of your very first debriefing session that you led.

What was the time frame in between? What pursued you to trial debriefing in your course?

Probes:

What factors (faculty, conferences, content in your course) influenced your decision to debrief?

\section{Question 3:}

When you reflect on implementing your first debriefing session, tell me about the debriefing session.

Probes:

What went as you expected, what went not as you expected? Tell me more about your debriefing experience what did you learn from your first conducted session? 


\section{Question 4:}

Let's talk about how you conduct debriefing sessions now. Tell me about a typical debriefing session - what do you do?

Probes:

Tell me how you have actively experimented with conducting debriefing sessions.

Are there any influences on your debriefing practice?

\section{Question 5:}

In what way has your debriefing changed over time?

Probes:

Length of debriefing session

Timeframe after simulation-based activities

Location of debriefing session

Who talks the most in the debriefing sessions?

\section{Question 6:}

From your perspective, how does the use of debriefing after simulation-based activities support your teaching your courses' objectives?

\section{Closing}

What advice would you give to faculty that are considering using debriefing after simulation-based activities in their course? 